Open Access

\title{
Metabolic, Endocrine, and Immune Consequences of Sleep Deprivation
}

\author{
Laila AlDabal ${ }^{1}$ and Ahmed S. BaHammam ${ }^{*}, 2$ \\ ${ }^{I}$ Department of Pulmonary Medicine, Rashid Hospital, Dubai Health Authority, United Arab Emirates \\ ${ }^{2}$ University Sleep Disorders Center, College of Medicine, King Saud University, Riyadh, Saudi Arabia
}

\begin{abstract}
Over the last three to four decades, it has been observed that the average total hours of sleep have decreased to less than seven hours per person per night. Concomitantly, global figures relating to obesity and diabetes mellitus have increased in an alarming fashion in adults and children, and it has been hypothesized that neuro-hormonal changes accompanying this behavioral sleep deprivation may lead to insulin resistance and, subsequently, to diabetes mellitus. Sleep deprivation has been associated with multiple physiological changes, including increased cortisol and ghrelin levels, decreased leptin levels and impaired glucose metabolism. Experimental studies have also shown an increase in inflammatory and pro-inflammatory markers, which are indicators of body stress, under sleep deprivation. This review elaborates further on this hypothesis, exploring the molecular basis for the link between both entities and the underlying pathophysiology that results in insulin resistance and diabetes mellitus. We review the results of experimental and epidemiological studies, specifically examining the relationship between sleep duration and the immune and endocrine systems.
\end{abstract}

Keywords: Sleep deprivation, obesity, glucose intolerance, insulin resistance, diabetes mellitus, ghrelin, leptin.

\section{INTRODUCTION}

Sleep is a complex and essential biological process that is required on a daily basis for all humans regardless of age, sex or ethnic origin. Despite extensive medical literature and advanced research in the field of sleep medicine, we still lack information on sleep physiology, and, to date, we still do not know the full spectrum of sleep functions. Although sleep is a vital process, we still do not fully understand why we sleep, what induces sleep, what induces wakefulness and how many hours are needed to achieve 'restorative sleep'. Learning, memory processing, cellular repair and brain development are among the most important functions of sleep [1-4]. Maintaining healthy sleep habits also has effects on neurobehavioral performance, and several studies have shown the deleterious effects of sleep deprivation, whether pathological or behavioral, on higher cognitive functioning [5-7]. Of note is the observation that significant interindividual differences exist in neurobehavioral responses to sleep deprivation that are not attributable to variations in sleep history [8]. Recent functional brain imaging studies on experimentally sleep-deprived subjects have confirmed these findings $[9,10]$.

In addition to maintaining normal brain functioning, sleep has important roles in controlling the functions of many other body systems, and this becomes very evident in states of sleep deprivation. It is becoming very clear that reducing the total hours of nocturnal sleep can lead to serious consequences for almost all bodily organs and systems.

*Address correspondence to this author at the University Sleep Disorders Center, College of Medicine, King Saud University, P.O. Box 225503, Riyadh 11324, Saudi Arabia; Tel: 966-1-467-9179; Fax: 966-1-467-9495; E-mail: ashammam2@gmail.com
Overall, immunity decreases [11], a state of systemic inflammation with increased inflammatory markers ensues $[12,13]$, and several hormones become upregulated [14]. Furthermore, people who stay awake for long periods of time may indulge in unhealthy behaviors and eating habits [15]. Clinically, sleep-deprived subjects are at higher risk of developing depression [16, 17], obesity [17], hypertension [18], dyslipedemia [19] and diabetes mellitus [20]. Recent data showed that sleep deprivation increases total daily energy expenditure in humans [21]. Sleep deprivation is not limited to a special group of people, a nation, a gender or a particular age group. Rather, it is a new human behavior observed among millions of adults and children worldwide. In addition, several epidemiological studies have demonstrated a link between shorter durations of sleep and increased mortality [22-24]. A very serious epidemiological observation made by several authors is that deviation from what are considered "normal" sleeping hours is associated with increased all-cause mortality [25-31]. In a cohort analysis by Ayas and his group, 71,617 health care workers (age 45-65 years) without cardiovascular diseases at enrollment were followed over 10 years to test for a link between sleep duration and the occurrence of cardiovascular events. After adjusting for associated cardiovascular risk factors, it was found that self-reported under-sleeping and over-sleeping were both independently associated with a modestly increased risk of coronary events [32]. The same study population was re-evaluated in a prospective observational fashion to determine the optimal sleep duration associated with lower cardiovascular risk. The study group concluded that mortality risk in women is lowest among those sleeping 6 to 7 hours [33]. Cardiovascular events and all-cause mortality were also found to be significantly associated with chronic insomnia among a group of ethnic 
Chinese in Taiwan in a recent report [26]. It is important to note that this is not a direct causal relationship between sleep duration and increased mortality, as multiple behavioral and co-morbid factors (age, gender, obesity, diabetes mellitus, hypertension and smoking) interact, with possible cumulative effects leading to the observed increases in mortality.

Sleep deprivation is becoming increasingly common in today's society. Compared to a few decades ago, major changes in sleep culture have been observed globally because there has been a trend toward adopting a 24/7 lifestyle, longer working hours and longer work shifts. This has led to a significant reduction in total sleeping hours in both adults and children.

In this review, we examine epidemiological and clinical data on immune, metabolic and endocrine manifestations of sleep restriction in children and adults and explore the molecular pathways linking reduced total sleep hours and increasing rates of obesity and metabolic syndromes globally. We will use the term behavioral sleep deprivation to differentiate from the pathological sleep deprivation seen with sleep-disordered breathing, pain syndromes and other medical illnesses.

\section{IMMUNE SYSTEM CONSEQUENCES OF SLEEP DEPRIVATION}

The field of cellular inflammatory molecules and mediators has expanded over recent decades to explore their serious and significant role in the pathogenesis and modulation of several physiological and pathological conditions. Currently, there is a plethora of clinical and experimental data on the interaction between sleep, inflammatory cascades, neuroendocrine functioning and the immune system [34-36]. New terms have been introduced into this field, such as white adipose tissue, adipokines, and adipose tissue hypoxia, and more terms will be used and described in future research papers as we expand our knowledge. van Leeuwen et al. studied the acute consequences of sleep deprivation and documented increased lymphocyte activation with overproductions of IL-1, IL-6 and IL-17; this group speculated that the same effects persist with long-term sleep deprivation and that this could be linked to an increase in cardiovascular events [37]. Interestingly, a gender difference between sleep duration and IL-6 and CRP was observed [38]. These findings were documented in another study on young, otherwise healthy women in which increased inflammatory markers accompanied disturbed sleep and were thought to be associated with gender specific chronic inflammatory diseases [39]. Several other studies have addressed changes in cytokine levels in response to sleep deprivation. Experimentally reduced sleep hours were found to be associated with increased daytime sleepiness, decreased performance and fatigue [40-44]. In a study of 8 young adults examining the relationship between sleep duration/quality and IL secretion, it was found that acute sleep deprivation increases daytime IL-6 and causes somnolence and fatigue during the following day, whereas post deprivation, night-time IL-6 is decreased and associated with deeper sleep [45]. Another study in 11 subjects suffering from chronic insomnia demonstrated that chronic insomnia is associated with a shift of IL-6 and TNF secretion from night-time to daytime, and this may explain the daytime fatigue and performance decrements associated with this disorder. The daytime shift of IL-6 and TNF secretion, combined with a 24-hour hypersecretion of cortisol (an arousal hormone), may explain insomniacs' daytime fatigue and difficulty in falling asleep [46].

\section{KEY POINTS}

- $\quad$ There is significant interaction between sleep and the immune system, and adequate "restorative" sleep is needed to maintain good immunity

- Sleep deprivation is associated with increased daytime sleepiness, reduced neuro-cognitive performance and fatigue

- Sleep deprivation is linked to increased daytime levels of inflammatory mediators such as IL-1, IL-6 and TNF

- Chronic sleep deprivation might be linked to increased all-cause morbidity and mortality

\section{METABOLIC AND ENDOCRINE CONSEQUENCES OF SLEEP DEPRIVATION}

Another important sequela of sleep deprivation is related to its effect on the metabolic and endocrine systems (Fig. 1). Subjects with poor sleep quality or duration may present to a cardiologist with uncontrolled hypertension or intractable heart failure; they might present to the endocrinologist with difficult-to-control blood sugar; or they could even present to the psychologist/psychiatrist with symptoms of chronic fatigue or depression. Accordingly, a high index of suspicion needs to be maintained, and a proper sleep history should be a fundamental part of every in-patient and out-patient evaluation. Unfortunately, there remains a large deficit in eliciting proper sleep histories in general medical and subspecialty clinics, and there is a significant delay before patients with serious sleep complaints are referred to sleep specialists for proper evaluation and timely management [47, 48].

The general link between sleep disorders and metabolic syndromes has been observed since the first descriptions of obese, heavy snoring subjects with or without obesity hypoventilation syndromes (among other sleep-disordered breathing patterns). This has rapidly grown with extensive research in the field of metabolic and endocrine consequences of sleep-disordered breathing, particularly obstructive sleep apnea (OSA) [49]. Several experimental and clinical studies have shown that frequent micro or macro arousals in OSA lead to repeated surges in the sympathetic nervous system and the loss of glucose and blood pressure control [50-53]. At the same time, many patients with diabetes mellitus suffer from OSA [54]. A common risk factor for both diseases would obviously be increased body mass index and adiposity $[55,56]$. Taken together, pathological sleep deprivation has been strongly linked to the development of glucose intolerance and hypertension. Along the same lines, data from epidemiological and experimental studies have pointed toward an association between behavioral sleep deprivation and the development of serious metabolic and endocrine consequences, particularly diabetes 
mellitus. An interesting study was conducted on a group of 11 young men who underwent an experimental sleep deprivation period and sleep extension period following normal baseline sleep duration over six nights. Glucose tolerance and the acute insulin response to glucose were significantly altered during the sleep-deprivation period [57]. Overall sleep architecture, especially slow-wave sleep (SWS) duration, is thought to contribute to glucose homeostasis, and this has been addressed in 2 recent studies $[58,59]$. In the first study, nine healthy lean adults underwent a baseline sleep study and oral glucose tolerance tests. Study subjects were then tested after 2 nights of undisturbed sleep and after 3 nights of experimental suppression of SWS. Importantly, SWS suppression led to reduced insulin sensitivity and a higher propensity for the development of diabetes mellitus without a compensatory rise in insulin release [58]. In the second study, 22 adults with diabetes mellitus were compared to a matched group of non-diabetics to assess the percentage of total sleep time in each stage of sleep. Subjects with diabetes mellitus had shorter SWS durations and higher arousal indices [59]. Several mechanisms are thought to interact to result in hyperglycemia and metabolic syndrome. Proposed mechanisms include alterations in glucose metabolism, upregulation of appetite and reduced energy expenditure as factors leading to the development of diabetes mellitus in subjects with chronic sleep deprivation [50]. In addition, hypoxemia (in patients with sleep disordered breathing) and a state of altered inflammatory and pro-inflammatory pathways exist that is accompanied by hormonal pathway changes that collectively cause similar metabolic derangements [60-68].

\section{KEY POINTS}

- $\quad$ There is a strong link between pathological sleep deprivation-for example, due to sleep-disordered breathing (in particular, OSA) - and metabolic syndrome/diabetes mellitus.

- Behavioral sleep deprivation results in alterations in glucose metabolism, upregulation of appetite and reduced energy expenditure.

- Behavioral sleep deprivation is associated with shorter SWS, increased levels of pro-inflammatory cytokines and low grade inflammation.

-

Significant hormonal changes affecting hypothalamic-pituitary-adrenal axis activity take place in the setting of sleep deprivation.

\section{SLEEP DURATION AND OBESITY EPIDEMICS; IS THERE A LINK?}

Sleep and feeding are both complex physiological processes requiring complex interactions between internal and external factors and pathways. On the surface, they pass as default human needs that are practiced without thinking on a daily basis since birth. However, exploring the molecular structure controlling both activities gives us an idea about the disorders that occur in abnormal states such as reduced sleep, oversleeping or abnormal feeding behaviors. In recent decades, there has been an exponential increase in our understanding of sleep and feeding physiology. One important epidemiological observation was that of the reciprocal relationship between sleep duration and the prevalence of global obesity over recent decades. Large scale epidemiological data from the United States and other parts of the world have consistently shown an overall increase in body mass index (BMI) over recent decades [69-74]. These figures are alarming and should be taken very seriously by governmental bodies and health care decision makers because obesity is closely linked to a number of serious medical illnesses, such as OSA, diabetes mellitus, hypertension and atherosclerosis, all of which cause huge economic burdens on both a short-term and a long-term basis and are predictors of increased morbidity and premature death [75-77]. Concomitant with the increase in the prevalence of global obesity, another "epidemic" was noticed, manifesting as significant changes in sleep habits with a trend toward sleep deprivation among children and adults. Kripke et al. presented data from a survey that was conducted in the Unites States in the 1960s describing an average sleep duration of 8 to 8.9 hours per night [78]. A few decades later, this figure had dropped to 7 hours per night [79]. More recent data shows a further drop in average levels of night-time sleep in adults to less than 6 hours [80]. In a recent cross-sectional population-based study in the United States, 110,441 adults older than 18 years were studied. Among the recruited subjects, $28.3 \%$ reported a sleep duration of $\leq 6$ hours, $63.3 \%$ reported a sleep duration of 7 or 8 hours and $8.5 \%$ reported sleeping $\geq 9$ hours [81]. Of note, all of these data were collected from self-reported questionnaires, indicating that they do not represent the actual sleep time. Subjects could be reporting time spent in bed rather than actual sleep duration. To overcome this lack of accuracy, a few studies were designed to use wrist actigraphy to measure total sleep time. One of the first studies to objectively assess sleep duration was conducted by Jean-Louis and colleagues on 273 adult volunteers using wrist actigraphy and showed an average sleep duration of 6.22 hours [82]. A larger group of participants was recruited in the CARDIA sleep study, where 669 adults (age 38-50 years, 58\% women and 44\% black) were assessed via sleep logs and wrist actigraphy [83]. This study showed interesting findings regarding the role of gender, race and socioeconomic status on overall quality of sleep and total sleep duration. The mean time in bed ranged from 7.8 hours for white women to 7.1 hours for black men, whereas mean sleep duration ranged from 6.7 hours for white women to 5.1 hours for black men. These researchers also found that actigraph-measured sleep duration was shorter than selfreported duration [83]. Redline et al. used polysomnography to assess sleep time in 2685 adults and demonstrated that the average sleep time was 6.1 hours for women and 5.7 hours for men [84]. A large subjective, population-based cohort study was conducted among Chinese adults in Singapore, where 58,044 subjects were recruited from the Singapore Chinese Health Study. Thirty-three percent of eligible subjects reported sleeping 7 hours per night, $27.49 \%$ reported sleeping 8 hours per night, $23.43 \%$ reported sleeping 6 hours per night, 9.38\% reported sleeping less than 5 hours per night and $6.63 \%$ reported sleeping more than 9 hours per night [85]. A larger cohort of 104,010 Japanese subjects was analyzed using self-reported data in the Japan Collaborative Cohort Study, and the analysis showed a mean sleep duration of 7.5 hours for men and 7.1 hours for women 
[86]. Differences obviously exist between self-reported sleep duration and objectively measured sleep duration that are affected by health status, socio-demographic data and sleep characteristics [87].

\section{KEY POINTS}

- There has been an overall global increase in BMI coinciding with shorter sleep durations over recent decades.

- $\quad$ Average length of sleep has dropped significantly to less than 7 hours per night.

- $\quad$ Objectively assessing sleep duration is more accurate than using self-reporting questionnaires.

- $\quad$ More long-term, large scale objective studies are needed to accurately assess the relationship between sleep duration and obesity

\section{SLEEP DEPRIVATION AND OBESITY IN CHILD- REN AND ADOLESCENTS}

Several studies have shown a decreasing trend in nocturnal sleep duration among children and young adolescents in various parts of the world [88-90]. Various studies have repeatedly confirmed the side effects of inadequate sleep on growing children and adolescents in particular. Several authors have studied acute and long-term behavioral and neuro-cognitive consequences in school children. Some of these studies were conducted in children and adolescents suffering from concomitant sleep-disordered breathing [91-93]. Fallone et al. examined the effects of acute sleep deprivation on the daytime behavior and performance of healthy children and adolescents. Eighty-two children (age 8 to 15 years) completed 5 nights of baseline sleep and were then randomly assigned to optimal (10 hours) or restricted (4 hours) sleep in the sleep laboratory. Sleep deprivation was associated with shorter daytime sleep latency, increased subjective sleepiness, and increased sleepy and inattentive behaviors [94]. Regarding the metabolic and endocrine consequences of sleep deprivation in children, an early observation of a possible link was made by Locard et al. in a study of obesity risk factors in a five year old population, and short sleep duration was identified as an important risk factor [95]. A Japanese group found a doseresponse relationship between short sleeping hours and childhood obesity in a sample of 8274 children (4194 males and 4080 females, age 6 to 7 years). Compared with children who had 10 or more hours of sleep, the adjusted odds ratio was 1.49 for those with 9 to 10 hours sleep, 1.89 for those with 8 to 9 hours sleep and 2.87 for those with $<8$ hours sleep [96]. Von Kries et al. conducted a cross-sectional study in 6862 German children (age 5 to 6 years) and found a negative correlation between sleep duration and the risk of developing obesity (10 hours, $5.4 \%$; $10.5-11.0$ hours, $2.8 \%$; and 11.5 hours, $2.1 \%$ ). This effect was confirmed after controlling for confounders such as parental obesity, socioeconomic status, and lifestyle factors [97]. Another large scale cross-sectional study was performed in 4511 children ( 7 to 9 years) and reported an inverse relationship between sleep duration and skin fold thickness as a measure of total body fat. That group identified sleep duration as a modifiable risk factor when managing childhood obesity [98]. The 'Québec en Forme' Project showed similar results in 422 children (5 to 10 years) [99]. Among Arab children, a sample of 5,877 Saudi children (age 10 to 19 years) was studied, and the study group showed that sleeping $\leq 7$ hours significantly increased the risk of obesity among boys and girls of all age groups [100]. Obviously, conducting longitudinal studies would be more informative in this regard. However, studies are limited with this design. Agras and his group followed 150 children from birth until the age of 9.5 and found a negative correlation between total sleep hours at the age of 3-5 years and body weight measured at the age of 9.5 years [101]. Taveras et al. conducted an interesting longitudinal study of 915 children who were followed from infancy until the age of 3 years and found that infant sleep of less than 12 hours per day was associated with a higher BMI and obesity [102]. A recent study by Snell et al. evaluated longitudinal data from a nationally representative sample of 2,281 American children (age 3 to 12 years). Baseline assessment of body mass index and body weight was performed at the age of 3 to 5 years and repeated 5 years later. There was a clear association between shorter sleep duration and future increases in body weight [103]. A larger group of children was evaluated for early obesity risk factors in a prospective cohort study in the UK. Short sleep duration was identified among 7 other risk factors predisposing children to childhood obesity [104]. In the longest prospective birth cohort study, 1037 participants born in Dunedin, New Zealand between April 1972 and March 1973 were recruited. Parents reported the sleep durations of the participating children at ages 5, 7, 9, and 11 years, and these data were analyzed in relation to the participants' BMIs at the age of 32 year. Interestingly, shorter childhood sleep times were significantly associated with higher adult body weights, and this association was present after adjusting for early childhood weight, socioeconomic status, parental BMIs and lifestyle [105]. Touchette at al. also conducted a longitudinal study of 1138 children where BMI was measured at ages 2.5 and 6 years. Sleep duration was reported yearly by their mothers. The study group identified 4 sleep duration patterns: short persistent (sleeping $<10$ hours per night: $5.2 \%$ ), short increasing (sleeping less than 10 hours per night at the age of 29 months to more than 10 hours per night at 41 months and maintaining this level until 74 months of age: $4.7 \%$ ), 10 hour persistent (sleeping persistently 10 hours per night: $50.7 \%$ ), and 11 hour persistent (sleeping 11 hours per night: 39.4\%). Persistently short sleep durations ( $<10$ hours) during early childhood significantly increased the risk of obesity by a factor of 4.2 compared to 11 hour persistent sleepers [106]. Wrist actigraphy was used to measure sleep duration in 591 children in New Zealand, and the results have been published recently. Mean time in bed according to parental reports was 10.9 hours, and mean sleep duration measured using actigraphy was 10.1 hours. In a multivariable analysis, sleep duration varied according to weekday, season, and the presence of younger siblings. Again, shorter sleep duration was found to be an independent risk factor for higher body weight in children [107]. Finally, a systematic review and meta-analysis of published data in this field, mainly from cross-sectional studies, was recently published by Chen et al. This review drew the following conclusions: 1) children with shorter sleep durations had a $58 \%$ higher risk for obesity, and children with the shortest sleep durations had an even 
greater risk (92\%) than children who had longer sleep durations. This risk is reduced by $9 \%$ for each hour increase in sleep duration. 2) There is a significant linear doseresponse relationship, but only in young children. 3 ) There is a significant gender difference (with a greater risk in boys) in the trend toward the development of obesity with shorter sleep durations [108].

\section{KEY POINTS}

- $\quad$ Sleep deprivation has detrimental effects on cognitive functioning and neurobehavioral performance in children and adolescents.

- There is a global epidemic of obesity among children and adolescents.

- There is significant correlation between shorter sleeping hours among children and adolescents and the development of obesity.

\section{SLEEP DEPRIVATION AND OBESITY IN ADULTS}

With regard to data concerning endocrine and metabolic consequences of voluntary or behavioral sleep deprivation in adults, we will review epidemiological and experimental studies in this field. Obesity is an important risk factor in the pathogenesis of various diseases such as diabetes mellitus, OSA and metabolic syndrome. More importantly, obesity was found to decrease life expectancy by 7 years at the age of 40 [76]. Obesity is known to be genetically and environmentally driven. One of the recently identified risk factors is a change in sleep quality or quantity. In recent decades, several studies have been conducted to determine whether there is a cause-effect relationship between sleep duration and body weight, and the data indicate that interpersonal differences in the sensitivity to sleep loss exist [109]. A cross-sectional study was conducted in 983 community-dwelling elderly subjects (age 57 to 97 years), among whom sleep duration was assessed using wrist actigraphy. The resulting data showed a significant U-shaped relationship with BMI, and both short sleepers ( $<5$ hours) and long sleepers $>8$ hours) were more likely to be obese [110]. Watanabe and his group conducted a prospective study in a large sample of Japanese employees $(35,247)$ with a 1 year follow-up to investigate the association between short sleep duration and elevated BMI and obesity. Short sleep duration was associated with weight gain and the development of obesity over 1 year in men, but not in women [111]. In a cross-sectional study that objectively assessed the association between sleep duration and body weight in elderly people, wrist actigraphy was performed in 3055 men (67-96 years) and 3052 women (age 70 to 99 years), and polysomnography was performed in a subgroup of 2862 men and 455 women. Compared to those sleeping an average of 7 to 8 hours per night, sleep duration of less than 5 hours was associated with a BMI that was on average 2.5 $\mathrm{kg} / \mathrm{m}^{2}$ greater in men and $1.8 \mathrm{~kg} / \mathrm{m}^{2}$ greater in women [112]. The same group also investigated the association between self-reported usual sleep duration and subsequent weight gain in the 68,183 women who participated in the Nurses' Health Study. It was found that women sleeping 5 hours or less gained $1.14 \mathrm{~kg}$ more than those who slept an average of 7 hours over 16 years, and women sleeping an average of 6 hours gained $0.71 \mathrm{~kg}$ more. The relative risks ratio of a 15 - $\mathrm{kg}$ weight gain were 1.32 and 1.12 for those sleeping 5 and 6 hours, respectively [113]. Data from the Quebec Family Study, which represents a 6 year observational study in 276 adults (age 21 to 64 years), provided evidence that long sleeping times predict an increased risk of future body weight and adipose tissue gains in adults [99]. López-García and her colleagues examined the association of habitual sleep duration with obesity and weight changes among 3576 persons aged 60 years or more in Spain. Subjects who slept 5 hours had a greater frequency of obesity with an odds ratio of 1.33 and a greater frequency of severe obesity with an odds ratio of 2.08 than subjects who slept 7 hours [114]. Vorona et al. examined the association between restricted sleep and obesity in a heterogeneous adult primary care population (924 patients, age 18 to 91 years). They found that the mean BMI was $30 \mathrm{~kg} / \mathrm{m}^{2}$, women slept more than men, and overweight and obese patients slept less than patients with a normal BMI [115]. Shigeta at al. found in 453 subjects (321 men and 131 women) that sleeping less than 6 hours was associated with an increased risk for the development of obesity [116]. A Korean group examined the association between sleep duration and general and abdominal obesity in 8,717 adults (age 20 to 65 years) from the Korean National Health and Nutrition Examination Survey (2001-2005). After controlling for sociodemographic and lifestyle factors, the adjusted odd ratios associated with sleeping 5 hours or less per day versus 7 hours per day were 1.25 for general obesity and 1.24 for abdominal obesity [117]. Hasler et al. tested the hypothesis that short sleep duration leads to weight gain during early adulthood [118]. This was a prospective single-age cohort study of 496 young adults with 4 interviews conducted at the ages of $27,29,34$, and 40 years. There was a clear association between short sleep duration and obesity at the age of 27 years. However, this association diminished after the age of 34 years [118]. Finally, in a systematic review of the current literature regarding short sleep duration as an independent risk factor for obesity and weight gain, the results from cross-sectional studies in adults were mixed. In contrast, longitudinal studies showed a positive association between short sleep duration and future weight gain [109]. In the second meta-analysis of data in this field, Cappuccio et al. pooled representative data from 26 studies including 604,509 adults worldwide and found a consistently increased risk of obesity among short sleepers in adults [119].

\section{KEY POINTS}

- Inter-personal variability exists in the sensitivity to sleep deprivation.

- $\quad$ Several epidemiological studies have shown a link between shorter sleep hours and obesity in adults

\section{SLEEP DEPRIVATION AND HYPERTENSION}

Sackner et al. in 1975 described patients with OSA as being chronically sleep deprived and noted that this condition was linked to the development of systemic arterial hypertension [120]. Ten years later, Tochikubo and his group monitored blood pressure in a group of young healthy males (age 23 to 48 years) who were experimentally sleep-deprived to a mean duration of 3.6 hours of sleep. Blood pressure, heart rate and urinary excretion of norepinephrine were all elevated on the following day [121]. Another group studied 
blood pressure, heart rate, forearm vascular resistance, and muscle sympathetic nerve activity measured at rest and during four stressors. These measures were obtained twice, initially after normal sleep and later after a night of sleep deprivation in 8 healthy subjects (age 35 to 45 years, six men and two women). Sleep deprivation resulted in an increase in blood pressure and a decrease in muscle sympathetic nerve activity [122]. Heart rate, forearm vascular resistance, and plasma catecholamines were not significantly changed by sleep deprivation, nor did sleep deprivation affect autonomic and hemodynamic responses to stressful stimuli [122]. In a longitudinal study (4810 subjects) that assessed the effect of short sleep duration on blood pressure and the risk for hypertension, Gangwisch et al. followed participants for 10 years, and hypertension was diagnosed in 647 subjects [123]. A sleep duration of 5 hours per night was associated with a significantly increased risk of hypertension, even after controlling for other risk factors [123]. A study of 6 young, healthy men who were acutely sleep-deprived showed that diastolic blood pressure was significantly higher after total sleep deprivation than after normal levels of sleep [124]. An interesting study was conducted by Irwin and Ziegler of 36 abstinent, alcohol-dependent men and 36 matched controls with similar baseline parameters [125]. Partial night sleep deprivation induced greater increases in heart rate and circulating levels of catecholamines in the alcohol-dependent men than in the controls [125]. Stranges et al. examined cross-sectional and prospective associations of sleep duration with prevalent and incident hypertension in a cohort of 10,308 British civil servants (age 35 to 55 years) and found a gender difference, where women were at a higher risk for developing hypertension than men [19]. A similar gender difference was found by Stang et al. when examining a cohort of subjects from the Heinz Nixdorf Recall Study, and sleeping for less than 5 hours per night was found to be a risk factor for hypertension in women [126]. Vgontzas et al. reported an association between sleep duration and hypertension in 1,741 men and women in a cross-sectional study. The risk was highest in subjects who slept less than 5 hours per night and in those with poor sleep quality [127]. A recent study in a group of 238 healthy adolescents used multiple-day wrist actigraphy at home and in-lab polysomnography for accurate sleep duration assessments [128]. Again, both short sleep duration and poor sleep quality were associated with a higher propensity for the development of hypertension [128].

\section{KEY POINTS}

- $\quad$ Sleep deprivation and poor sleep quality are associated with higher risks of developing hypertension.

- $\quad$ There might be a gender difference in response to sleep deprivation and the development of hypertension

\section{SLEEP DEPRIVATION AND DYSLIPIDEMIA}

Recent data suggest an association between sleep deprivation and dyslipidemia. Kaneita at al. examined the individual association between sleep duration and high serum triglycerides, low HDL (high-density lipoproteins) cholesterol, or high LDL (low-density lipoproteins) cholesterol levels. The study analyzed data from the National Health and Nutrition Survey including 1,666 men and 2,329 women aged 20 years or older and showed that among women, sleeping less than 5 hours per night or more than 8 hours per night were associated with high serum triglyceride levels or low HDL cholesterol levels [129]. Importantly, this finding was persistent even after adjusting for confounders [129]. The Hordaland Health Study evaluated sleep habits in 8860 subjects (aged 40 to 45 years) and compared them to body weight, blood pressure, total cholesterol, HDL cholesterol and triglyceride levels. Short sleep durations were associated with elevated BMIs, higher non-fasting levels of cholesterol and triglycerides, and higher systolic and diastolic blood pressures [20]. A recent study of a large group of young adults ( 14,257 subjects) who were followed from 1994 to 2002 showed that short sleep durations could be a significant risk factor for hypercholesterolemia in young adults and, in particular, females [123]. The authors suggested that lengthening sleep could potentially both treat and act a primary preventative measure for hypercholesterolemia. The Rotterdam Study, on the other hand, used wrist actigraphy to assess sleep duration in an older group of subjects (768 subjects, age 57 to 97 years) [130]. Sleep duration and sleep quality were associated with higher cholesterol levels [130].

\section{KEY POINTS}

- Sleep deprivation may be associated with higher serum levels of cholesterol and triglycerides.

- Women could be at a higher risk of developing dyslipidemia with sleep deprivation.

\section{SLEEP DEPRIVATION, GLUCOSE INTOLERANCE, DIABETES MELLITUS AND METABOLIC SYNDROMES}

As mentioned earlier, both feeding and sleeping/waking cycles are under tight hypothalamic control, and abnormal patterns in one axis would obviously affect the other. This interactive relationship could explain why people who sleep less tend to eat more or why people who eat more tend to sleep more. Over the next few paragraphs, we will review the epidemiological and experimental data linking sleep deprivation and the development of insulin resistance, glucose intolerance, diabetes mellitus and the metabolic syndrome. Robin et al. conducted an impressive study published in 1959 examining changes in blood glucose levels in 8 normal, healthy adults and 16 young diabetics [131]. Hourly measurements of blood glucose in both groups showed tight control of blood glucose with essentially constant levels in healthy subjects, whereas patients with diabetes showed marked variations in blood glucose levels during sleep [131]. Thereafter, several other well-designed studies explored the nocturnal control of blood glucose and examined changes in insulin release and blood glucose levels among other physiological changes that take place during sleep [132, 133]. Internationally, diabetes mellitus figures are increasing, and it is estimated that the prevalence in adults worldwide will be approximately $5.4 \%$ by the year 2025 [134]. In the following paragraphs, we will review the epidemiological and experimental data linking behavioral sleep deprivation to the development of diabetes mellitus and discuss the underlying pathophysiology. 


\section{Epidemiological Studies (Table 1)}

Several studies have described the association between this voluntary or behavioral sleep deprivation and the development of glucose intolerance, insulin resistance, diabetes mellitus and metabolic syndrome, and taken together, they form the basis for the hypothesis that a major contributor to obesity and the metabolic syndrome epidemic is shorter sleep. Chaput et al. used self-reported sleep duration questionnaires to assess the relationship between sleep duration and diabetes mellitus or impaired glucose tolerance. A cross-sectional sample of 323 men and 417 women was examined (age 21 to 64 years, taken from the Quebec Family Study), where adults with 7 to 8 hours of sleep were used as a reference. Subjects who slept for 5 to 6 hours had an odd ratio of 2.09 for impaired glucose tolerance compared to those who slept for 7 to 8 hours [135]. Two studies from Sweden conducted in healthy subjects revealed a propensity for the development of diabetes mellitus among those with shorter sleep durations. The first study included a random sample of 2,663 subjects (age 45 to 65 years) who responded to a questionnaire addressing behavioral and lifestyle activities [136]. Twelve years later, 1,244 surviving subjects responded to a second, identical questionnaire. The investigators found that men, but not women, with sleep durations of $<5$ hours tended to develop diabetes mellitus upon follow-up after adjusting for other risk factors [136]. The second study included a group of 6,599 initially healthy, non-diabetic men (age 40.5 to 48.5 years) [137]. Selfreported questionnaires and blood glucose levels were used in this prospective study, which showed that people reporting poor sleep quality had a higher probability of being diagnosed with diabetes mellitus upon follow-up [137]. Tuomilehto et al. conducted the FIN-D2D survey, which was a population-based cross-sectional multicenter study in Finland that included 1336 men and 1434 women (age 45 to 74 years). The authors found that sleeping for $\leq 6$ hours was independently associated with the presence of diabetes mellitus in middle-aged women, but not in men [138]. Meisinger et al. studied gender difference regarding the risk of developing diabetes mellitus with shorter sleep durations, comparing 4,140 men and 4,129 women (age 25 to 74 years). Over a follow-up period of 7.5 years, 119 men and 69 women developed diabetes mellitus [139]. Along the same lines, data from Southeast Asia have shown that difficulty in initiating sleep and shorter sleep durations are significant risk factors driving glucose metabolism dysregulation [140142], and data from the US have shown similar results. In a study by Vgontzas et al., 1741 men and women underwent polysomnography to objectively assess sleep duration, and this was related with glucose profiles [127]. The investigators found that chronic insomniacs with shorter sleep durations had higher odds ratios for the development of glucose dysregulation and diabetes mellitus [127]. A second study by Gangwisch et al. was a multivariate longitudinal analysis of the NHANES I trial, which included 8992 subjects over 10 years (age 32 to 86 years). Again, shorter sleep was proposed as a risk factor for diabetes mellitus [143]. A third cross-sectional study conducted in a group of African-Americans with underlying diabetes mellitus (161 subjects) showed that $71 \%$ of the participants had poor quality sleep and this, in addition to shorter sleep duration, was associated with higher $\mathrm{HbA} 1 \mathrm{C}$ levels. This indicated that poor sleep quality/duration not only induces hyperglycemia but also worsens glucose control in those already diagnosed with diabetes mellitus [144]. Xu et al. and his group reported that day-napping and short nocturnal sleep duration are associated with a higher risk of diabetes [145]. In the Western New York Health Study, Rafalson et al. followed 1,455 healthy individuals over a 6 year period. Subjects sleeping less than 6 hours per night had significantly higher fasting blood glucose, which is thought to be mediated by insulin resistance [146]. Yaggi and his group assessed the long-term relationship between sleep duration and the incidence of diabetes mellitus [147]. Importantly, men reporting sleeping 6 hours were twice as likely to develop diabetes mellitus, whereas those sleeping $>$ 8 hours per night were more than three times as likely to develop diabetes mellitus over the follow-up period [147]. Hall et al. evaluated 1,214 adults in a cross-sectional community-based cohort study. Short sleep, which was associated with higher BMIs, higher fasting blood glucose levels and dyslipidemia, was also a significant risk factor for metabolic syndrome [148]. Similar results were found by analyzing the Quebec Family Study [149]. Finally, 3 recent studies released in 2010 have examined the association between sleep duration and glucose dysregulation in young women of child bearing age, and interesting results were found. The first study, conducted by Taveras et al., examined the association of short sleep duration among women in the first year postpartum with metabolic parameter changes 3 years postpartum. This group found that sleeping less than 5 hours increased the risk of adiposity several years later without any significant change in metabolic parameters [150]. The remaining 2 studies were conducted among pregnant women and showed that snoring and self-reported short sleep duration were significantly associated with gestational glucose intolerance and diabetes mellitus [151$153]$.

\section{Laboratory Studies (Table 2)}

One of the first studies exploring the effects of partial recurrent sleep deprivation on glucose metabolism was conducted by Spiegel et al. on 11 young men who underwent 6 nights of sleep deprivation (4 hours in bed) and 7 nights of sleep recovery (12 hours in bed) with a simultaneous intravenous (IV) glucose tolerance test. Glucose tolerance was lower and cortisol levels were higher in the sleep-debt condition compared to the fully rested condition [154]. Donga et al. evaluated the effect of a single night of partial sleep restriction on parameters relating to insulin sensitivity in 9 healthy subjects who were studied using polysomnography and hyperinsulinemic euglycemic clamp studies [155]. After one night of experimental sleep deprivation, the measurements showed increased endogenous glucose production and reduced glucose disposal rates, reflecting insulin resistance [155]. Insulin sensitivity was also reduced in another study where investigators experimentally induced fragmented sleep over 2 nights in 11 healthy volunteers, and a decrease in insulin sensitivity and glucose effectiveness associated with increased sympathetic activity was noted [156]. Spiegel et al. conducted another randomized cross-over study in 12 young, healthy men who were subjected to 2 consecutive nights of sleep restriction followed by 2 nights of sleep extension. 
Table 1. Summary of Epidemiological Studies on Sleep Deprivation and Diabetes Mellitus

\begin{tabular}{|c|c|c|c|c|}
\hline First Author & Year & Sample & Study Duration & Comments \\
\hline Chaput et al. [135] & 2007 & 740 & 3 years & Sleeping $<6$ hours led to impaired glucose tolerance. \\
\hline Mallonet al. [136] & 2005 & 2663 & 12 years & $\begin{array}{c}\text { Difficulties maintaining sleep or short sleep duration are associated with } \\
\text { increased incidence of diabetes in men. }\end{array}$ \\
\hline Nilsson et al. [137] & 2004 & 6599 & $14.8 \pm 2.4$ years & Sleep disturbances increased risk of diabetes. \\
\hline Tuomilehto et al. [138] & 2008 & 2800 & 2 years & $\begin{array}{c}\text { Short ( } \leq 6 \text { hours) or long } \geq 8 \mathrm{~h} \text { ) sleep duration increased risk of type } 2 \text { diabetes } \\
\text { in middle-aged women but not in men. }\end{array}$ \\
\hline Meisinger et al. [139] & 2005 & 8300 & 11 years & $\begin{array}{c}\text { Difficulty maintaining sleep was associated with an increased risk of type } 2 \\
\text { diabetes in men and women. }\end{array}$ \\
\hline Hayashino et al. [140] & 2007 & 6509 & 6 years & $\begin{array}{c}\text { Difficulty initiating sleep was associated with higher risks of diabetes } \\
\text { in relatively healthy adults. }\end{array}$ \\
\hline Kawakami et al. [141] & 2004 & 2649 & 8 years & Sleep disturbances associated with 2-3 higher risk of diabetes. \\
\hline Choi et al. [142] & 2008 & 4222 & 1 year & $\begin{array}{l}\text { Both short and long sleep durations was related to increased risk } \\
\text { of the metabolic syndrome. }\end{array}$ \\
\hline Gangwisch et al. [143] & 2007 & 8992 & 10 years & Short sleep duration could be a significant risk factor for diabetes. \\
\hline Xu et al. $[145]$ & 2010 & 10143 & 10 years & Day napping and short night sleeping was associated with diabetes. \\
\hline Rafalson et al. [146] & 2010 & 1455 & 6 years & $\begin{array}{l}\text { Short sleep duration was associated with elevated risk of impaired } \\
\text { fasting glucose, mediated via insulin resistance. }\end{array}$ \\
\hline Yaggi et al. [147] & 2006 & 1709 & 18 years & Short and long sleep durations increase risk of diabetes. \\
\hline Hall et al. [148] & 2008 & 1214 & cross-sectional study & Sleep duration is a significant correlate of the metabolic syndrome. \\
\hline Facco et al. [163] & 2010 & 189 & During Pregnancy & Short sleep duration was associated with glucose intolerance in pregnancy. \\
\hline Qui et al. [153] & 2010 & 1290 & During Pregnancy & $\begin{array}{l}\text { The results suggest an association of short sleep duration with glucose } \\
\text { intolerance and gestational diabetes. }\end{array}$ \\
\hline
\end{tabular}

Intravenous glucose was used as a calorie source after the second night. Major changes in the daytime profile of insulin, glucose and ghrelin-to-leptin ratio were seen among the sleep-restricted group, with the decrease in leptin being a stronger predictor of change in appetite than the increase in ghrelin [157]. This effect on leptin and ghrelin release was also observed by Schmid and his group, who studied 9 healthy men under 3 sleeping conditions: one night with a total sleep time of 7 hours, one night with a total sleep time of 4.5 hours and one night with total sleep deprivation [158]. Study subjects reported stronger feelings of hunger after total sleep deprivation than under the other 2 conditions, with higher ghrelin levels accompanying these feelings [158]. A recently published trial by Buxton and his colleagues included 12 healthy men (age 20 to 35 years) who were subjected to one week of sleep deprivation followed by an intravenous glucose tolerance test and, in accordance with previous study results, sleep deprivation led to a significant reduction in insulin sensitivity [159].

Few recent meta-analyses and systemic reviews of medical literature in this evolving branch of sleep medicine have thoroughly addressed the limitations of these epidemiological and laboratory studies and highlighted the importance of conducting well-designed, large scale and controlled studies with long follow-up time frames to address these significant findings. Furthermore, these studies should assess sleep duration objectively, rather than relying on self-reported questionnaires [50,160,161].

Taken together, a strong body of evidence is accumulating that indicates a close association between reduced sleeping hours and the development of metabolic syndromes affecting both children and adults. Proposed mechanisms include increased sympathetic arousal, changes in hormonal pathways and up-regulated inflammatory cascades, as discussed previously. A very important observation was made by King and his group regarding the association between sleep duration and the risk of developing coronary artery calcification, and despite the significant limitations of that study, this remains a significant finding, as the authors stated that each extra hour of sleep per night decreased the estimated odds of calcification by $33 \%$ [162]. We believe that this association needs to be taken seriously given the deleterious effect of poor sleep quality/quantity on the risk of metabolic syndrome and cardiovascular mortality and morbidity.

\section{CONCLUSION AND FUTURE DIRECTIONS}

Sleep and eating are vital physiological processes that are linked via a complicated network of hormonal pathways, and losing the homeostasis of one process exerts deleterious effects on the other during both the short and the long term. The link between over- and under-sleeping and glucose dysregulation is a very serious breakthrough in our understating of obesity, diabetes mellitus and metabolic syndrome pathophysiology, and this should be addressed more methodically by epidemiologists and researchers to identify optimal sleeping hours. For the time being, no strong recommendations can be made as to how many hours of restorative sleep we actually need to maintain a healthy life and normal body weight and to avoid the development of the above-mentioned serious metabolic consequences. 
Table 2. Summary of Experimental Studies on Sleep Deprivation and Diabetes Mellitus

\begin{tabular}{|c|c|c|c|c|}
\hline First Author & Year & Sample & Study Duration & Comments \\
\hline \hline Spiegel et al. [154] & 1999 & 11 & 6 Nights & Sleep debt has a harmful impact on carbohydrate metabolism. \\
\hline Donga et al. [155] & 2010 & 9 & 1 Night & Partial sleep deprivation during a single night induces glucose intolerance. \\
\hline Stamatakis \& Punjabi [156] & 2010 & 11 & 2 Nights & Fragmentation of sleep across all stages is associated with diabetes. \\
\hline Spiegel et al. [157] & 2004 & 12 & 4 Nights & $\begin{array}{c}\text { Short sleep duration is associated with decreased leptin levels, increased ghrelin } \\
\text { levels, increased hunger and appetite. }\end{array}$ \\
\hline Schmid et al. [158] & 2008 & 9 & 1 Night & One night of sleep deprivation increased ghrelin levels. \\
\hline Buxton et al. [159] & 2010 & 20 & 1 Week & Sleep restriction (5 hours/night) for 1 week significantly reduces insulin sensitivity. \\
\hline
\end{tabular}

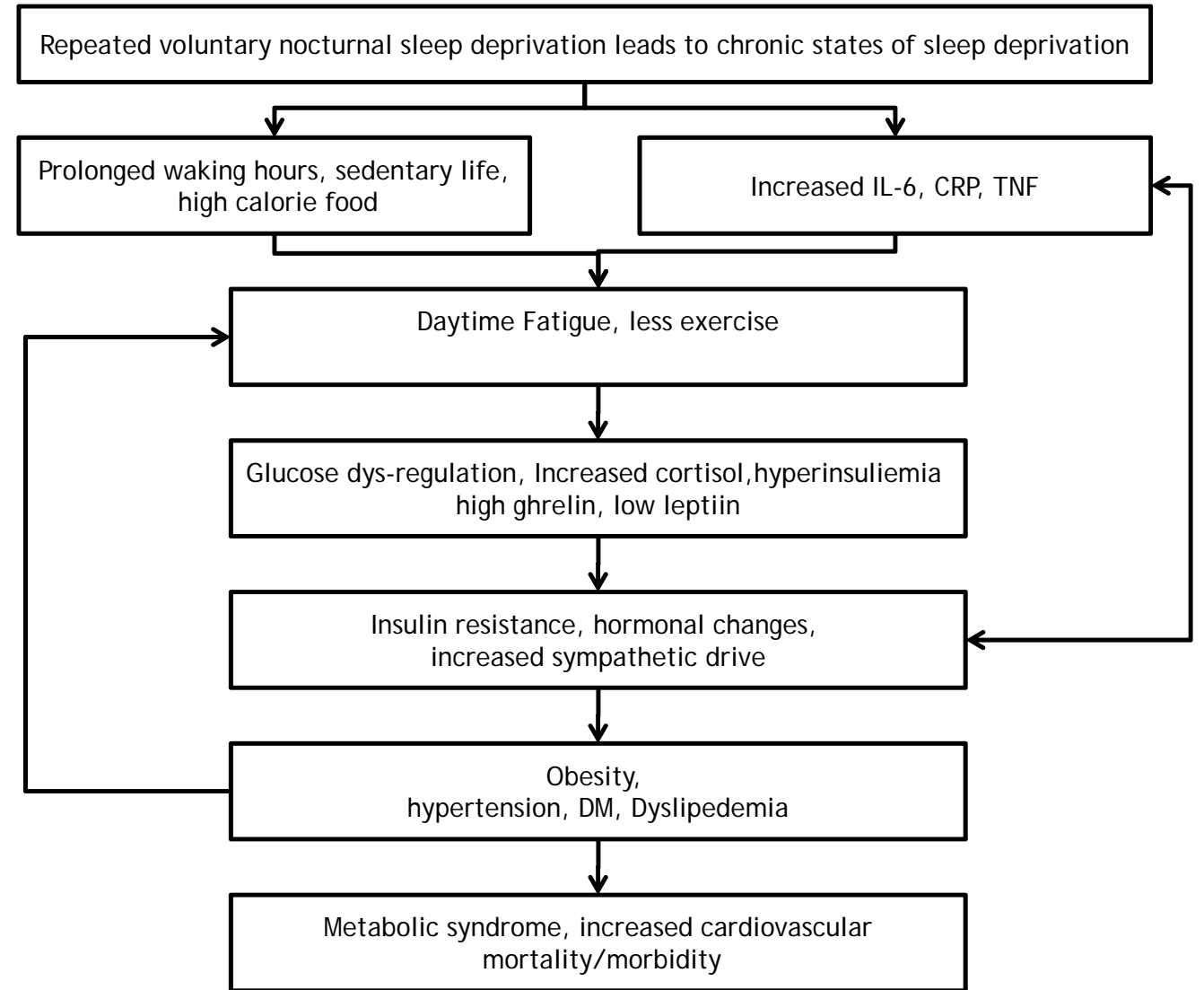

Fig. (1). Proposed algorithm for the interaction between sleep deprivation and metabolic changes.

\section{ACKNOWLEDGEMENT}

This work was partially supported by a grant from King Abdulaziz City for Science and Technology (KACST) and the University Sleep Disorders Center, King Saud University.

\section{REFERENCES}

[1] Tononi G, Cirelli C. Sleep function and synaptic homeostasis. Sleep Med Rev 2006;10(1): 49-62.

[2] Dinges DF. The state of sleep deprivation: from functional biology to functional consequences. Sleep Med Rev 2006; 10(5): 303-5.

[3] Stickgold R, Walker MP. Sleep-dependent memory consolidation and reconsolidation. Sleep Med 2007; 8(4): 331-43.

[4] Peirano PD, Algarin CR. Sleep in brain development. Biol Res 2007; 40(4): 471-8.
[5] Durmer JS, Dinges DF. Neurocognitive consequences of sleep deprivation. Semin Neurol 2005; 25(1): 117-29.

[6] Banks S, Dinges DF. Behavioral and physiological consequences of sleep restriction. J Clin Sleep Med 2007; 3(5): 519-28.

[7] Van Dongen HP, Maislin G, Mullington JM, Dinges DF. The cumulative cost of additional wakefulness: dose-response effects on neurobehavioral functions and sleep physiology from chronic sleep restriction and total sleep deprivation. Sleep 2003; 26(2): 117-26.

[8] Van Dongen HP, Baynard MD, Maislin G, Dinges DF. Systematic interindividual differences in neurobehavioral impairment from sleep loss: evidence of trait-like differential vulnerability. Sleep 2004; 27(3): 423-33.

[9] Beebe DW, Difrancesco MW, Tlustos SJ, McNally KA, Holland SK. Preliminary fMRI findings in experimentally sleep-restricted adolescents engaged in a working memory task. Behav Brain Funct 2009; 5: 9 . 
[10] Chee MW, Chuah LY. Functional neuroimaging insights into how sleep and sleep deprivation affect memory and cognition. Curr Opin Neurol 2008; 21(4): 417-23.

[11] Spiegel K, Sheridan JF, Van Cauter E. Effect of sleep deprivation on response to immunization. JAMA 2002; 288(12): 1471-2.

[12] Irwin MR, Wang M, Campomayor CO, Collado-Hidalgo A, Cole S. Sleep deprivation and activation of morning levels of cellular and genomic markers of inflammation. Arch Intern Med 2006; 166(16): 1756-62.

[13] Irwin MR, Wang M, Ribeiro D, et al. Sleep loss activates cellular inflammatory signaling. Biol Psychiatry 2008; 64(6): 538-40.

[14] Kotronoulas G, Stamatakis A, Stylianopoulou F. Hormones, hormonal agents, and neuropeptides involved in the neuroendocrine regulation of sleep in humans. Hormones (Athens) 2009; 8(4): 23248.

[15] Nedeltcheva AV, Kilkus JM, Imperial J, Kasza K, Schoeller DA, Penev PD. Sleep curtailment is accompanied by increased intake of calories from snacks. Am J Clin Nutr 2009; 89(1): 126-33.

[16] Ross LE, McLean LM. Anxiety disorders during pregnancy and the postpartum period: a systematic review. J Clin Psychiatry [Comparative Study Research Support, Non-U.S. Gov't Review] 2006; 67(8): 1285-98.

[17] Dorheim SK, Bondevik GT, Eberhard-Gran M, Bjorvatn B. Sleep and depression in postpartum women: a population-based study. Sleep 2009; 32(7): 847-55.

[18] Prinz P. Sleep, appetite, and obesity--what is the link? PLoS Med 2004; 1(3): e61.

[19] Stranges S, Dorn JM, Cappuccio FP, et al. A population-based study of reduced sleep duration and hypertension: the strongest association may be in premenopausal women. J Hypertens 2010; 28(5): 896-902.

[20] Gottlieb DJ, Punjabi NM, Newman AB, et al. Association of sleep time with diabetes mellitus and impaired glucose tolerance. Arch Intern Med [Comparative Study Research Support, U.S. Gov't, P.H.S.] 2005; 165(8): 863-7.

[21] Jung CM, Melanson EL, Frydendall EJ, Perreault L, Eckel RH, Wright K. Energy expenditure during sleep, sleep deprivation and sleep following sleep deprivation in adult humans. J Physiol 2011; 589(Pt 1): 235-44.

[22] Grandner MA, Hale L, Moore M, Patel NP. Mortality associated with short sleep duration: The evidence, the possible mechanisms, and the future. Sleep Med Rev 2010; 14(3): 191-203.

[23] Vgontzas AN, Liao D, Pejovic S, et al. Insomnia with short sleep duration and mortality: the Penn State cohort. Sleep 2010; 33(9): 1159-64.

[24] Castro-Costa E, Dewey ME, Ferri CP, et al. Association between sleep duration and all-cause mortality in old age: 9-year follow-up of the Bambui Cohort Study, Brazil. J Sleep Res 2011; 20(2): 30310.

[25] Cappuccio FP, D'Elia L, Strazzullo P, Miller MA. Sleep duration and all-cause mortality: a systematic review and meta-analysis of prospective studies. Sleep 2010; 33(5): 585-92.

[26] Chien KL, Chen PC, Hsu HC, et al. Habitual sleep duration and insomnia and the risk of cardiovascular events and all-cause death: report from a community-based cohort. Sleep 2010; 33(2): 177-84.

[27] Ikehara S, Iso H, Date C, et al. Association of sleep duration with mortality from cardiovascular disease and other causes for Japanese men and women: the JACC study. Sleep 2009; 32(3): 295-301.

[28] Stone KL, Ewing SK, Ancoli-Israel S, et al. Self-reported sleep and nap habits and risk of mortality in a large cohort of older women. J Am Geriatr Soc 2009; 57(4): 604-11.

[29] Gangwisch JE, Heymsfield SB, Boden-Albala B, et al. Sleep duration associated with mortality in elderly, but not middle-aged, adults in a large US sample. Sleep 2008; 31(8): 1087-96.

[30] Kripke DF, Garfinkel L, Wingard DL, Klauber MR, Marler MR. Mortality associated with sleep duration and insomnia. Arch Gen Psychiatry 2002; 59(2): 131-6.

[31] Punjabi NM, Caffo BS, Goodwin JL, et al. Sleep-disordered breathing and mortality: a prospective cohort study. PLoS Med 2009; 6(8): e1000132.

[32] Ayas NT, White DP, Manson JE, et al. A prospective study of sleep duration and coronary heart disease in women. Arch Intern Med 2003; 163(2): 205-9.

[33] Patel SR, Ayas NT, Malhotra MR, et al. A prospective study of sleep duration and mortality risk in women. Sleep 2004; 27(3): $440-4$.
[34] Imeri L, Opp MR. How (and why) the immune system makes us sleep. Nat Rev Neurosci 2009; 10(3): 199-210.

[35] Born J, Fehm HL. The neuroendocrine recovery function of sleep. Noise Health 2000; 2(7): 25-38.

[36] Lange T, Dimitrov S, Fehm HL, Westermann J, Born J. Shift of monocyte function toward cellular immunity during sleep. Arch Intern Med 2006; 166(16): 1695-700.

[37] van Leeuwen WM, Lehto M, Karisola P, et al. Sleep restriction increases the risk of developing cardiovascular diseases by augmenting proinflammatory responses through IL-17 and CRP. PLoS One 2009; 4(2): e4589.

[38] Miller MA, Kandala NB, Kivimaki M, et al. Gender differences in the cross-sectional relationships between sleep duration and markers of inflammation: Whitehall II study. Sleep 2009; 32(7): 857-64.

[39] Okun ML, Coussons-Read M, Hall M. Disturbed sleep is associated with increased C-reactive protein in young women. Brain Behav Immun 2009; 23(3): 351-4.

[40] Vgontzas AN, Mastorakos G, Bixler EO, Kales A, Gold PW, Chrousos GP. Sleep deprivation effects on the activity of the hypothalamic-pituitary-adrenal and growth axes: potential clinical implications. Clin Endocrinol (Oxf) 1999; 51(2): 205-15.

[41] Papanicolaou DA, Wilder RL, Manolagas SC, Chrousos GP. The pathophysiologic roles of interleukin-6 in human disease. Ann Intern Med 1998; 128(2): 127-37.

[42] Redwine L, Hauger RL, Gillin JC, Irwin M. Effects of sleep and sleep deprivation on interleukin-6, growth hormone, cortisol, and melatonin levels in humans. J Clin Endocrinol Metab 2000; 85(10): 3597-603.

[43] Vgontzas AN, Bixler EO, Lin HM, Prolo P, Trakada G, Chrousos GP. IL-6 and its circadian secretion in humans. Neuroimmunomodulation 2005; 12(3): 131-40.

[44] Lim W, Hong S, Nelesen R, Dimsdale JE. The association of obesity, cytokine levels, and depressive symptoms with diverse measures of fatigue in healthy subjects. Arch Intern Med 2005; 165(8): 910-5.

[45] Vgontzas AN, Papanicolaou DA, Bixler EO, et al. Circadian interleukin-6 secretion and quantity and depth of sleep. J Clin Endocrinol Metab 1999; 84(8): 2603-7.

[46] Vgontzas AN, Zoumakis M, Papanicolaou DA, et al. Chronic insomnia is associated with a shift of interleukin-6 and tumor necrosis factor secretion from nighttime to daytime. Metabolism 2002; 51(7): 887-92.

[47] Sorscher AJ. How is your sleep: a neglected topic for health care screening. J Am Board Fam Med 2008; 21(2): 141-8.

[48] BaHammam AS. Knowledge and attitude of primary health care physicians towards sleep disorders. Saudi Med J 2000; 21(12): 1164-7.

[49] Levy P, Bonsignore MR, Eckel J. Sleep, sleep-disordered breathing and metabolic consequences. Eur Respir J 2009; 34(1): 243-60.

[50] Knutson KL, Spiegel K, Penev P, Van Cauter E. The metabolic consequences of sleep deprivation. Sleep Med Rev 2007; 11(3): 163-78.

[51] Theorell-Haglow J, Berne C, Janson C, Lindberg E. Obstructive sleep apnoea is associated with decreased insulin sensitivity in females. Eur Respir J 2008; 31(5): 1054-60.

[52] Reichmuth KJ, Austin D, Skatrud JB, Young T. Association of sleep apnea and type II diabetes: a population-based study. Am J Respir Crit Care Med 2005; 172(12): 1590-5.

[53] Schultes B, Schmid S, Peters A, Born J, Fehm HL. Sleep loss and the development of diabetes: a review of current evidence. Exp Clin Endocrinol Diabetes 2005; 113(10): 563-7.

[54] Lamond N, Tiggemann M, Dawson D. Factors predicting sleep disruption in Type II diabetes. Sleep 2000; 23(3): 415-6.

[55] West SD, Nicoll DJ, Stradling JR. Prevalence of obstructive sleep apnoea in men with type 2 diabetes. Thorax 2006; 61(11): 945-50.

[56] Punjabi NM, Shahar E, Redline S, Gottlieb DJ, Givelber R, Resnick HE. Sleep-disordered breathing, glucose intolerance, and insulin resistance: the sleep heart health study. Am J Epidemiol 2004; 160(6): 521-30.

[57] Allen RP. Article reviewed: impact of sleep dept on metabolic and endocrine function. Sleep Med 2000; 1(2): 149-50.

[58] Tasali E, Leproult R, Ehrmann DA, Van Cauter E. Slow-wave sleep and the risk of type 2 diabetes in humans. Proc Natl Acad Sci USA 2008; 105(3): 1044-9. 
[59] Pallayova M, Donic V, Gresova S, Peregrim I, Tomori Z. Do differences in sleep architecture exist between persons with type 2 diabetes and nondiabetic controls? J Diabetes Sci Technol 2010; 4(2): 344-52.

[60] Frey DJ, Fleshner M, Wright KP Jr. The effects of 40 hours of total sleep deprivation on inflammatory markers in healthy young adults. Brain Behav Immun 2007; 21(8): 1050-7.

[61] Ye J. Emerging role of adipose tissue hypoxia in obesity and insulin resistance. Int J Obes (Lond) 2009; 33(1): 54-66.

[62] Ding Q, Mracek T, Gonzalez-Muniesa P, et al. Identification of macrophage inhibitory cytokine- 1 in adipose tissue and its secretion as an adipokine by human adipocytes. Endocrinology 2009; 150(4): 1688-96.

[63] Davidson JR, Moldofsky H, Lue FA. Growth hormone and cortisol secretion in relation to sleep and wakefulness. J Psychiatry Neurosci 1991; 16(2): 96-102.

[64] Charloux A, Gronfier C, Lonsdorfer-Wolf E, Piquard F, Brandenberger G. Aldosterone release during the sleep-wake cycle in humans. Am J Physiol 1999; 276(1 Pt 1): E43-9.

[65] Schussler P, Yassouridis A, Uhr M, et al. Growth hormonereleasing hormone and corticotropin-releasing hormone enhance non-rapid-eye-movement sleep after sleep deprivation. Am J Physiol Endocrinol Metab 2006; 291(3): E549-56.

[66] Nindl BC, Rarick KR, Castellani JW, et al. Altered secretion of growth hormone and luteinizing hormone after $84 \mathrm{~h}$ of sustained physical exertion superimposed on caloric and sleep restriction. J Appl Physiol 2006; 100(1): 120-8.

[67] Balbo M, Leproult R, Van Cauter E. Impact of sleep and its disturbances on hypothalamo-pituitary-adrenal axis activity. Int $\mathbf{J}$ Endocrinol 2010; 759234.

[68] Lui MM, Ip MS. Disorders of glucose metabolism in sleepdisordered breathing. Clin Chest Med 2010; 31(2): 271-85.

[69] No Authors Listed. Vital signs: state-specific obesity prevalence among adults --- United States, 2009. MMWR Morb Mortal Wkly Rep 2010; 59(30): 951-5.

[70] James PT, Rigby N, Leach R. The obesity epidemic, metabolic syndrome and future prevention strategies. Eur J Cardiovasc Prev Rehabil 2004; 11(1): 3-8.

[71] Martorell R, Khan LK, Hughes ML, Grummer-Strawn LM. Obesity in women from developing countries. Eur J Clin Nutr 2000; 54(3): 247-52.

[72] de Onis M, Blossner M. Prevalence and trends of overweight among preschool children in developing countries. Am J Clin Nutr 2000; 72(4): 1032-9

[73] Chopra M, Galbraith S, Darnton-Hill I. A global response to a global problem: the epidemic of overnutrition. Bull World Health Organ 2002; 80(12): 952-8.

[74] Reilly JJ. Obesity in childhood and adolescence: evidence based clinical and public health perspectives. Postgrad Med J 2006; 82(969): 429-37.

[75] Anderson P. Reducing overweight and obesity: closing the gap between primary care and public health. Fam Pract 2008; 25(Suppl 1): $10-6$

[76] Peeters A, Barendregt JJ, Willekens F, Mackenbach JP, Al Mamun A, Bonneux L. Obesity in adulthood and its consequences for life expectancy: a life-table analysis. Ann Intern Med 2003; 138(1): 2432.

[77] Haffey TA. How to avoid a heart attack: putting it all together. J Am Osteopath Assoc 2009; 109(5 Suppl): S14-20.

[78] Kripke DF, Simons RN, Garfinkel L, Hammond EC. Short and long sleep and sleeping pills. Is increased mortality associated? Arch Gen Psychiatry 1979; 36(1): 103-16.

[79] Knutson KL, Van Cauter E, Rathouz PJ, DeLeire T, Lauderdale DS. Trends in the prevalence of short sleepers in the USA: 19752006. Sleep 2010; 33(1): 37-45.

[80] Centers for Disease Control and Prevention,. Percentage of Adults Who Reported an Average of $<6$ Hours of Sleep per 24-Hour Period, by Sex and Age Group- United States, 1985 and 2004. MMWR 2005; 54(37): 933.

[81] Krueger PM, Friedman EM. Sleep duration in the United States: a cross-sectional population-based study. Am J Epidemiol 2009; 169(9): 1052-63.

[82] Jean-Louis G, Kripke DF, Ancoli-Israel S. Sleep and quality of well-being. Sleep 2000; 23(8): 1115-21.
[83] Lauderdale DS, Knutson KL, Yan LL, et al. Objectively measured sleep characteristics among early-middle-aged adults: the CARDIA study. Am J Epidemiol 2006; 164(1): 5-16.

[84] Redline S, Kirchner HL, Quan SF, Gottlieb DJ, Kapur V, Newman A. The effects of age, sex, ethnicity, and sleep-disordered breathing on sleep architecture. Arch Intern Med 2004; 164(4): 406-18.

[85] Shankar A, Koh WP, Yuan JM, Lee HP, Yu MC. Sleep duration and coronary heart disease mortality among Chinese adults in Singapore: a population-based cohort study. Am J Epidemiol 2008; 168(12): 1367-73.

[86] Tamakoshi A, Ohno Y. Self-reported sleep duration as a predictor of all-cause mortality: results from the JACC study, Japan. Sleep 2004; 27(1): 51-4.

[87] Lauderdale DS, Knutson KL, Yan LL, Liu K, Rathouz PJ. Selfreported and measured sleep duration: how similar are they? Epidemiology 2008; 19(6): 838-45.

[88] BaHammam A, Bin Saeed A, Al-Faris E, Shaikh S. Sleep duration and its correlates in a sample of Saudi elementary school children. Singapore Med J 2006 ; 47(10): 875-81.

[89] Gibson ES, Powles AC, Thabane L, et al. "Sleepiness" is serious in adolescence: two surveys of 3235 Canadian students. BMC Public Health 2006; 6: 116.

[90] Iglowstein I, Jenni OG, Molinari L, Largo RH. Sleep duration from infancy to adolescence: reference values and generational trends. Pediatrics 2003; 111(2): 302-7.

[91] Blunden SL, Beebe DW. The contribution of intermittent hypoxia, sleep debt and sleep disruption to daytime performance deficits in children: consideration of respiratory and non-respiratory sleep disorders. Sleep Med Rev 2006; 10(2): 109-18.

[92] Beebe DW. Neural and neurobehavioral dysfunction in children with obstructive sleep apnea. PLoS Med 2006; 3(8): e323.

[93] Wolfson AR, Carskadon MA. Sleep schedules and daytime functioning in adolescents. Child Dev 1998; 69(4): 875-87.

[94] Fallone G, Acebo C, Arnedt JT, Seifer R, Carskadon MA. Effects of acute sleep restriction on behavior, sustained attention, and response inhibition in children. Percept Mot Skills 2001; 93(1): 213-29.

[95] Locard E, Mamelle N, Billette A, Miginiac M, Munoz F, Rey S. Risk factors of obesity in a five year old population. Parental versus environmental factors. Int J Obes Relat Metab Disord 1992; 16(10): 721-9.

[96] Sekine M, Yamagami T, Handa K, et al. A dose-response relationship between short sleeping hours and childhood obesity: results of the Toyama Birth Cohort Study. Child Care Health Dev 2002; 28(2): 163-70.

[97] von Kries R, Toschke AM, Wurmser H, Sauerwald T, Koletzko B. Reduced risk for overweight and obesity in 5- and 6-y-old children by duration of sleep--a cross-sectional study. Int J Obes Relat Metab Disord 2002; 26(5): 710-6.

[98] Padez C, Mourao I, Moreira P, Rosado V. Long sleep duration and childhood overweight/obesity and body fat. Am J Hum Biol 2009; 21(3): 371-6.

[99] Chaput JP, Despres JP, Bouchard C, Tremblay A. The association between sleep duration and weight gain in adults: a 6-year prospective study from the Quebec Family Study. Sleep 2008; 31(4): 517-23.

[100] Bawazeer NM, Al-Daghri NM, Valsamakis G, et al. Sleep duration and quality associated with obesity among Arab children. Obesity (Silver Spring) 2009; 17(12): 2251-3.

[101] Agras WS, Hammer LD, McNicholas F, Kraemer HC. Risk factors for childhood overweight: a prospective study from birth to 9.5 years. J Pediatr 2004; 145(1): 20-5.

[102] Taveras EM, Rifas-Shiman SL, Oken E, Gunderson EP, Gillman MW. Short sleep duration in infancy and risk of childhood overweight. Arch Pediatr Adolesc Med 2008; 162(4): 305-11.

[103] Snell EK, Adam EK, Duncan GJ. Sleep and the body mass index and overweight status of children and adolescents. Child Dev 2007; 78(1): 309-23.

[104] Reilly JJ, Armstrong J, Dorosty AR, et al. Early life risk factors for obesity in childhood: cohort study. BMJ 2005; 330(7504): 1357.

[105] Landhuis CE, Poulton R, Welch D, Hancox RJ. Childhood sleep time and long-term risk for obesity: a 32-year prospective birth cohort study. Pediatrics 2008; 122(5): 955-60.

[106] Touchette E, Petit D, Tremblay RE, et al. Associations between sleep duration patterns and overweight/obesity at age 6. Sleep 2008; 31(11): 1507-14. 
[107] Nixon GM, Thompson JM, Han DY, et al. Short sleep duration in middle childhood: risk factors and consequences. Sleep 2008; 31(1): 71-8.

[108] Chen X, Beydoun MA, Wang Y. Is sleep duration associated with childhood obesity? A systematic review and meta-analysis. Obesity (Silver Spring) 2008; 16(2): 265-74.

[109] Ezzati M, Lopez AD, Rodgers A, Vander Hoorn S, Murray CJ. Selected major risk factors and global and regional burden of disease. Lancet 2002; 360(9343): 1347-60.

[110] van den Berg JF, Knvistingh NA, Tulen JH, et al. Actigraphic sleep duration and fragmentation are related to obesity in the elderly: the Rotterdam Study. Int J Obes (Lond) 2008; 32(7): 1083-90.

[111] Watanabe M, Kikuchi H, Tanaka K, Takahashi M. Association of short sleep duration with weight gain and obesity at 1-year followup: a large-scale prospective study. Sleep 2010; 33(2): 161-7.

[112] Patel SR, Blackwell T, Redline S, et al. The association between sleep duration and obesity in older adults. Int J Obes (Lond) 2008; 32(12): 1825-34.

[113] Patel SR, Malhotra A, White DP, Gottlieb DJ, Hu FB. Association between reduced sleep and weight gain in women. Am J Epidemiol 2006; 164(10): 947-54.

[114] Lopez-Garcia E, Faubel R, Leon-Munoz L, Zuluaga MC, Banegas JR, Rodriguez-Artalejo F. Sleep duration, general and abdominal obesity, and weight change among the older adult population of Spain. Am J Clin Nutr 2008; 87(2): 310-6.

[115] Vorona RD, Winn MP, Babineau TW, Eng BP, Feldman HR, Ware JC. Overweight and obese patients in a primary care population report less sleep than patients with a normal body mass index. Arch Intern Med 2005; 165(1): 25-30.

[116] Shigeta H, Shigeta M, Nakazawa A, Nakamura N, Yoshikawa T. Lifestyle, obesity, and insulin resistance. Diabetes Care 2001; 24(3): 608.

[117] Park SE, Kim HM, Kim DH, Kim J, Cha BS, Kim DJ. The association between sleep duration and general and abdominal obesity in Koreans: data from the Korean National Health and Nutrition Examination Survey, 2001 and 2005. Obesity 2009; 17(4): 767-71.

[118] Hasler G, Buysse DJ, Klaghofer R, et al. The association between short sleep duration and obesity in young adults: a 13-year prospective study. Sleep 2004; 27(4): 661-6.

[119] Cappuccio FP, Taggart FM, Kandala NB, et al. Meta-analysis of short sleep duration and obesity in children and adults. Sleep 2008; 31(5): 619-26

[120] Sackner MA, Landa J, Forrest T, Greeneltch D. Periodic sleep apnea: chronic sleep deprivation related to intermittent upper airway obstruction and central nervous system disturbance. Chest 1975; 67(2): 164-71.

[121] Tochikubo O, Ikeda A, Miyajima E, Ishii M. Effects of insufficient sleep on blood pressure monitored by a new multibiomedical recorder. Hypertension 1996; 27(6): 1318-24.

[122] Kato M, Phillips BG, Sigurdsson G, Narkiewicz K, Pesek CA, Somers VK. Effects of sleep deprivation on neural circulatory control. Hypertension 2000; 35(5): 1173-5.

[123] Gangwisch JE, Malaspina D, Babiss LA, et al. Short sleep duration as a risk factor for hypercholesterolemia: analyses of the National Longitudinal Study of Adolescent Health. Sleep 2010; 33(7): 95661.

[124] Ogawa Y, Kanbayashi T, Saito Y, et al. Total sleep deprivation elevates blood pressure through arterial baroreflex resetting: a study with microneurographic technique. Sleep 2003; 26(8): 986-9.

[125] Irwin MR, Ziegler M. Sleep deprivation potentiates activation of cardiovascular and catecholamine responses in abstinent alcoholics. Hypertension 2005; 45(2): 252-7.

[126] Stang A, Moebus S, Mohlenkamp S, Erbel R, Jockel KH. Genderspecific associations of short sleep duration with prevalent hypertension. Hypertension 2008; 51(3): e15-6.

[127] Vgontzas AN, Liao D, Bixler EO, Chrousos GP, Vela-Bueno A. Insomnia with objective short sleep duration is associated with a high risk for hypertension. Sleep 2009; 32(4): 491-7.

[128] Javaheri S, Storfer-Isser A, Rosen CL, Redline S. Sleep quality and elevated blood pressure in adolescents. Circulation 2008; 118(10): 1034-40.

[129] Kaneita Y, Uchiyama M, Yoshiike N, Ohida T. Associations of usual sleep duration with serum lipid and lipoprotein levels. Sleep 2008; 31(5): 645-52.
[130] van den Berg JF, Miedema HM, Tulen JH, et al. Long sleep duration is associated with serum cholesterol in the elderly: the rotterdam study. Psychosom Med 2008; 70(9): 1005-11.

[131] Robin ED, Travis DM, Julian DG, Boshell BR. Metabolic patterns during physiologic sleep. I. Blood glucose regulation during sleep in normal and diabetic subjects. J Clin Invest 1959; 38: 2229-33.

[132] Boden G, Ruiz J, Urbain JL, Chen X. Evidence for a circadian rhythm of insulin secretion. Am J Physiol 1996; 271(2 Pt 1): E24652.

[133] Scheen AJ, Van Cauter E. The roles of time of day and sleep quality in modulating glucose regulation: clinical implications. Horm Res 1998; 49(3-4): 191-201.

[134] King H, Aubert RE, Herman WH. Global burden of diabetes, 19952025: prevalence, numerical estimates, and projections. Diabetes Care 1998; 21(9): 1414-31.

[135] Chaput JP, Despres JP, Bouchard C, Tremblay A. Association of sleep duration with type 2 diabetes and impaired glucose tolerance. Diabetologia 2007; 50(11): 2298-304.

[136] Mallon L, Broman JE, Hetta J. High incidence of diabetes in men with sleep complaints or short sleep duration: a 12-year follow-up study of a middle-aged population. Diabetes Care 2005; 28(11): 2762-7.

[137] Nilsson PM, Roost M, Engstrom G, Hedblad B, Berglund G. Incidence of diabetes in middle-aged men is related to sleep disturbances. Diabetes Care 2004 ; 27(10): 2464-9.

[138] Tuomilehto H, Peltonen M, Partinen M, et al. Sleep duration is associated with an increased risk for the prevalence of type 2 diabetes in middle-aged women - The FIN-D2D survey. Sleep Med 2008; 9(3): 221-7.

[139] Meisinger C, Heier M, Loewel H. Sleep disturbance as a predictor of type 2 diabetes mellitus in men and women from the general population. Diabetologia 2005; 48(2): 235-41.

[140] Hayashino Y, Fukuhara S, Suzukamo Y, Okamura T, Tanaka T, Ueshima H. Relation between sleep quality and quantity, quality of life, and risk of developing diabetes in healthy workers in Japan: the High-risk and Population Strategy for Occupational Health Promotion (HIPOP-OHP) Study. BMC Public Health 2007; 7: 129.

[141] Kawakami N, Takatsuka N, Shimizu H. Sleep disturbance and onset of type 2 diabetes. Diabetes Care 2004; 27(1): 282-3.

[142] Choi KM, Lee JS, Park HS, Baik SH, Choi DS, Kim SM. Relationship between sleep duration and the metabolic syndrome: Korean National Health and Nutrition Survey 2001. Int J Obes (Lond) 2008; 32(7): 1091-7.

[143] Gangwisch JE, Heymsfield SB, Boden-Albala B, et al. Sleep duration as a risk factor for diabetes incidence in a large U.S. sample. Sleep 2007; 30(12): 1667-73.

[144] Knutson KL, Ryden AM, Mander BA, Van Cauter E. Role of sleep duration and quality in the risk and severity of type 2 diabetes mellitus. Arch Intern Med 2006; 166(16): 1768-74.

[145] Xu Q, Song Y, Hollenbeck A, Blair A, Schatzkin A, Chen H. Day napping and short night sleeping are associated with higher risk of diabetes in older adults. Diabetes Care 2010; 33(1): 78-83.

[146] Rafalson L, Donahue RP, Stranges S, et al. Short sleep duration is associated with the development of impaired fasting glucose: the Western New York Health Study. Ann Epidemiol 2010; 20(12): 883-9.

[147] Yaggi HK, Araujo AB, McKinlay JB. Sleep duration as a risk factor for the development of type 2 diabetes. Diabetes Care 2006; 29(3): 657-61.

[148] Hall MH, Muldoon MF, Jennings JR, Buysse DJ, Flory JD, Manuck SB. Self-reported sleep duration is associated with the metabolic syndrome in midlife adults. Sleep 2008; 31(5): 635-43.

[149] Chaput JP, Despres JP, Bouchard C, Astrup A, Tremblay A. Sleep duration as a risk factor for the development of type 2 diabetes or impaired glucose tolerance: analyses of the Quebec Family Study. Sleep Med 2009; 10(8): 919-24.

[150] Taveras EM, Rifas-Shiman SL, Rich-Edwards JW, Gunderson EP, Stuebe AM, Mantzoros CS. Association of maternal short sleep duration with adiposity and cardiometabolic status at 3 Years postpartum. Obesity (Silver Spring) 2011; 191: 171-8.

[151] Facco FL, Grobman WA, Kramer J, Ho KH, Zee PC. Self-reported short sleep duration and frequent snoring in pregnancy: impact on glucose metabolism. Am J Obstet Gynecol 2010; 203(2): 142 e1-5.

[152] Facco FL, Grobman WA, Kramer J, Ho KH, Zee PC. Self-reported short sleep duration and frequent snoring in pregnancy: impact on glucose metabolism. Am J Obstet Gynecol 2010; 203(2): 142.e1-5. 
[153] Qiu C, Enquobahrie D, Frederick IO, Abetew D, Williams MA. Glucose intolerance and gestational diabetes risk in relation to sleep duration and snoring during pregnancy: a pilot study. BMC Womens Health 2010; 10: 17.

[154] Spiegel K, Leproult R, Van Cauter E. Impact of sleep debt on metabolic and endocrine function. Lancet 1999; 354(9188): 14359.

[155] Donga E, van Dijk M, van Dijk JG, et al. A single night of partial sleep deprivation induces insulin resistance in multiple metabolic pathways in healthy subjects. J Clin Endocrinol Metab 2010; 95(6): 2963-8.

[156] Stamatakis KA, Punjabi NM. Effects of sleep fragmentation on glucose metabolism in normal subjects. Chest 2010; 137(1): 95101.

[157] Spiegel K, Tasali E, Penev P, Van Cauter E. Brief communication: Sleep curtailment in healthy young men is associated with decreased leptin levels, elevated ghrelin levels, and increased hunger and appetite. Ann Intern Med 2004 ; 141(11): 846-50.
[158] Schmid SM, Hallschmid M, Jauch-Chara K, Born J, Schultes B. A single night of sleep deprivation increases ghrelin levels and feelings of hunger in normal-weight healthy men. J Sleep Res 2008; 17(3): 331-4.

[159] Buxton OM, Pavlova M, Reid EW, Wang W, Simonson DC, Adler GK. Sleep restriction for 1 week reduces insulin sensitivity in healthy men. Diabetes 2010; 59(9): 2126-33.

[160] Knutson KL. Impact of sleep and sleep loss on glucose homeostasis and appetite regulation. Sleep Med Clin 2007; 2(2): 187-97.

[161] Spiegel K, Knutson K, Leproult R, Tasali E, Van Cauter E. Sleep loss: a novel risk factor for insulin resistance and Type 2 diabetes. J Appl Physiol 2005; 99(5): 2008-19.

[162] King CR, Knutson KL, Rathouz PJ, Sidney S, Liu K, Lauderdale DS. Short sleep duration and incident coronary artery calcification. JAMA 2008; 300(24): 2859-66.

[163] Facco FL, Kramer J, Ho KH, Zee PC, Grobman WA. Sleep disturbances in pregnancy. Obstet Gynecol 2010; 115(1): 77-83.

(C) AlDabal and BaHammam; Licensee Bentham Open.

This is an open access article licensed under the terms of the Creative Commons Attribution Non-Commercial License (http://creativecommons.org/licenses/ by-nc/3.0/) which permits unrestricted, non-commercial use, distribution and reproduction in any medium, provided the work is properly cited. 